\title{
Characterization of Bioconcrete and the Properties for Self-Healing ${ }^{\dagger}$
}

\author{
Lais Alves 1,* , Leniza Alves ${ }^{2}$, Murilo Mello ${ }^{3}$ and Silvio de Barros 4 \\ 1 Department of Mechanical Engineering, Federal Center of Technological Education Celso Suckow da \\ Fonseca, Rio de Janeiro 20271-110, Brazil \\ 2 Polytechnic School, Federal University of Rio de Janeiro, Rio de Janeiro 21941-909, Brazil; \\ alves.leniza@gmail.com \\ 3 Departament of Civil Engineering, Veiga de Almeida University, Rio de Janeiro 20271-020, Brazil; \\ murilomonfort@gmail.com \\ 4 GeM-Research Institute in Civil and Mechanical Engineering, Université de Nantes, Nantes 44600, France; \\ silvio.debarros@gmail.com \\ * Correspondence: lais.alves@cefet-rj.br \\ + Presented at the 5th Ibero-American Congress on Entrepreneurship, Energy, \\ Environment and Technology-CIEEMAT, Portalegre, Portugal, 11-13 September 2019.
}

Published: 26 December 2019

\begin{abstract}
Concrete is the most widely used material in the world. It is a material with several advantages such as cost, ease of execution, adaptation to different shapes, satisfactory resistance to atmospheric effects, thermal and mechanical resistance, and extended life span. Therefore, the quest for its improvement is constant. Despite all these advantages, it presents a pathological manifestation intrinsic to the material itself-the appearance of cracks-which, depending on the cause, generates very high maintenance and conservation costs and can compromise the entire structure. Despite all preventive measures, it is not always possible to avoid the appearance of this pathology, which tends to intensify the constant search for greater use of its resistance. To remedy this problem, a Dutch microbiologist has developed a bio-based self-regenerating concrete that can not only reduce the need and, consequently, costs for maintenance of the concrete structure, but also increase its durability.
\end{abstract}

Keywords: bioconcrete; self-healing concrete; self-healing materials; cracks

\section{Introduction}

Properties are designed and built to meet the needs of the users for a long period. To attend the expected lifespan, the constant practice of preventive maintenance is essential [1]. Concrete is the first option when building something to have a long useful life, which makes it one of the most used materials in construction in general. Despite every attempt already used in the search for its improvement, it still presents considerable failures. Regardless of any care in mixing and reinforcement, the material will eventually crack by expansion and contraction, which results in an unattractive appearance, and can also compromise the entire structure of the building. Some treatments for this problem are known, but the remarkable prevention technique and the possible solution to this pathological manifestation came from a Dutch microbiologist. 
To solve the problem of cracks in concrete structures, researcher Hendrik Marius Jonkers observed that the human body, including the bone structure, can heal minor damage on its own. Through this inspiration, he came to a type of concrete that heals naturally: the self-healing bioconcrete. The use of this new material in new constructions and maintenance of existing structures will substantially reduce the costs of preserving a concrete structure. This work aims to outline the concepts of self-regeneration, reliability and accessibility, and how the bioconcrete can help mitigate this pathological manifestation, reducing the need for corrective maintenance.

\section{Armed Concrete and Pathologies}

Reinforced concrete is the most widely used construction material in the world. Low production costs, ease of execution, adaptation to any shape (providing architectural freedom), an excellent solution for obtaining a monolithic and hyper-static structure (better security reserves), resistance to atmospheric, thermal and up to mechanical resistance, virtually no maintenance and excellent durability are among the advantages of the materials. The disadvantages are high self-weight (of the order of $2.5 \mathrm{t} / \mathrm{m}^{3}$ ), low thermal protection and acoustic insulation, besides cracking of the traction region, which can, however, be controlled using traction armor [2].

The presence of cracks in the surface of reinforced concrete structures is one of the most common pathologies. It is a natural and inevitable phenomenon of concrete predisposed to aggravate by the increasing search for the use of the resistance of its components and can manifest itself in each of the three phases of its life: plastic, hardening, and hardened concrete [3]. The most common causes of fissures are concrete dryness (poorly executed cure), retraction, temperature variation, environmental aggression, accidents, corrosion of the reinforcement, load, design errors, insufficient design details, execution errors, foundations settlement and structural loads (stress, compression, bending and shear).

The buildings in recent years have quality levels that can generally be considered unsatisfactory, reverting to problems passed on to users and to costs of recovery and maintenance whose magnitude is significant [3]. Dal Molin [4] carried out a comparative study in 1988 assessing the initial cost of a quality structure added its maintenance cost per year of service and, a low-quality structure and lower initial amount. The conclusion is that the second structure requires higher maintenance costs than the first one, and that the total long-term price of the quality structure is lower than the longterm price of the low-quality one. The therapeutic methods of correction of the pathological manifestations include small punctual repairs, generalized restoration of the structure or reinforcement of pillars, beams, slabs or foundations [4].

The chance of limiting the frequency of pathologies in the constructions depends on all involved in the process-designers, manufacturers, constructors and users. In order to obtain a quality concrete, it is vital to take care of the choice of its materials, the determination of a trace that guarantees the strength and the desired durability, the homogenization of the mixture, its correct application and densification, until the proper "cure" - which will ensure the perfect hydration of the cement, besides correctly following the procedures of the technical standards [5].

\section{Concrete Self-Regeneration Potential}

The lack of quality and the premature failure of the ageing infrastructure has a very high cost. Of the 600,000 bridges in the US, one in four needs to be modernised or repaired, about $10 \%$ are considered structurally deficient, and $10 \%$ are considered functionally obsolete. In the Netherlands, one-third of the annual budget for major civil engineering works is spent on inspection, monitoring, maintenance, modernisation, and repair, while in the UK repair and maintenance costs account for almost $45 \%$ [5].

From materials science, the focus to change this scenario lies in the proactive management of ageing structures. A possible way to achieve this would be by using self-regenerating materials which could extend the life of structures, resulting in reduced maintenance costs, less use of scarce resources, energy and need for transportation related to the manufacturing of materials. 
The traditional way of making things better is to make them stronger and rigid, so material technology has been steadily moving in the direction of high and ultra-high strength. The project philosophy that focuses on damage prevention, using stronger materials has been called Damage Prevention Paradigm (DPP) [5], and claims that improving the resistance of the material will undoubtedly increase its ability to withstand loads and delay the moment the first damage occurs. However, once concrete cracking begins, the decay rate is relatively high, and manual repair is required.

On the other hand, there is the Damage Control Paradigm (DCP) [5], where a degree of damage is considered not only acceptable but also supposedly necessary to initiate an intrinsic mechanism of self-repair or self-healing. The material is designed so that small cracks or other damage mechanisms can occur to trigger an autonomous self-healing process-or produced without external influencethat will bring the material back to its original performance level as shown in Figure 1.
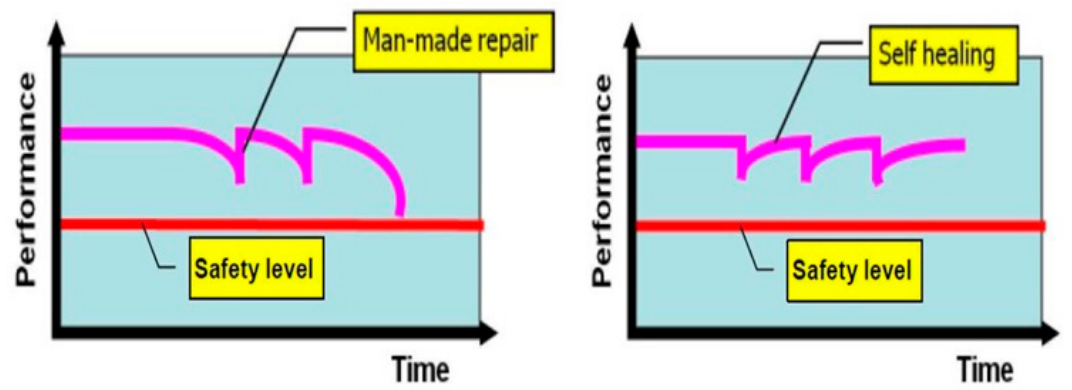

Figure 1. Damage Prevention Paradigm (DPP) - Manual Repair (left) and Damage Control Paradigm (DCP)-Self Regeneration (right) [5].

These two design paradigms are applicable for most materials, but not so well for reinforced concrete because it is brittle with microcracks even before the application of any load. Therefore, from a material science perspective, a concrete project will always be within the DCP, although the cracks are not considered damages but an intrinsic characteristic to the concrete and are acceptable provided that the criteria defined by technical norms are not exceeded. From a safety point of view, their presence is not a cause for concern. However, they are undesirable in terms of overall performance, especially durability, aesthetics, and functionality.

\subsection{Biobased Auto Regeneration}

One of the preconditions for self-regeneration of cracks in concrete is the transport of material into the crack. In a living organism, the transport of ingredients takes place through a vascular system. Plants and trees transport the elements through a network of pores. A porous material such as concrete also has a pore system through which the transport process is possible.

The expectation in this question is the concept of the bacterial-based crack repair mechanism (Figure 2), in which after breaking, the bacteria present in the cracks of the fresh surface of the concrete, begins to multiply with the presence of water by precipitating minerals such as calcium carbonate to close the fissures, protecting the steel from external chemical attack.

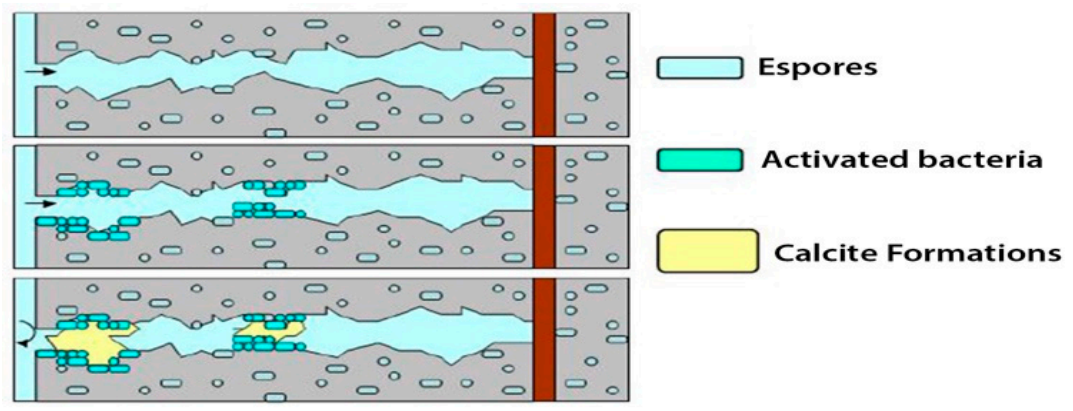

Figure 2. Bacteria Based Crack Repair Mechanism [5]. 
Jonkers [6] began his study of biologically based self-regenerative concrete with the search for a bacterium that could potentially act as a healing agent in concrete. The prerequisite for a successful repair process is the bacterium's survival at the high $\mathrm{pH}$ (around 12 to 13) of the concrete. It has been discovered that, from the microbiological point of view, the addition of bacteria to concrete or even concrete as an environment for a specific bacterium, is not uncommon. Although the concrete initially appears inhospitable due to its high alkalinity, it is known that natural systems are comparatively even drier environments in which bacteria can survive [7].

This desiccation and alkalinity resistant bacteria, when in environments that threaten their survival, usually form spores - a layer that protects bacteria, making them able to withstand high levels of stress induced mechanically and chemically. The bacteria that develop this layer have a very long life-the spores are known to last up to 200 years if kept in a dry state and at average temperatures [6].

Bacteria to be used in the concrete as a self-repair agent should be work-appropriate, i.e., they should be capable of performing effective sealing of cracks in the long term, preferably for the entire life of a structure. The main mechanism of bacterial cure of cracks is that the bacteria themselves act primarily as a machine by turning a precursor compound into a suitable filler. Thus, to obtain a concrete having the actual self-curing characteristic, both the bacteria and the precursor compound must be incorporated into the matrix from time zero, i.e., from dosing.

Bacteria that can resist incorporation into concrete mortar exist in nature, appear to be related to a specific group of bacteria resistant to alkalinity and have an impressive characteristic, the ability to form spores-which are specific spherical and thick cells with a diameter of $1 \mu \mathrm{m}$ and somehow homologous to plant seeds. They are cells in good condition, but inactive, that can withstand mechanical and chemical tensions and remain in a dry state for periods superior to 50 years [6].

But Jonkers [7] found that when bacterial spores were added directly to the concrete mix, their life span was limited to 1-2 months and attributed the decrease of the life span to the continuous hydration of the cement, what results in spore diameters much smaller than bacterial spores of $1 \mu \mathrm{m}$. Another concern was whether the direct addition of biomineral precursor organic compounds to the mortar would not result in an undesirable loss of other concrete properties. Many organic binder precursor compounds, such as yeast extract, peptone, and calcium acetate, have resulted in a dramatic decrease in compressive strength. However, the addition of calcium lactate had promising results with a $10 \%$ increase in compressive strength compared to the control samples [6].

In order to increase the life span, the associated functionality of the bacteria in the concrete, the effect of bacterial spores and the simultaneously required biomineral organic compound precursor (calcium lactate), Jonkers [7] tested the immobilization of these components on porous expanded clay particles what has been found to have substantially prolonged the shelf life (Figure 3). After six months of incorporation into the concrete, no loss of spore effectiveness was observed, suggesting its good long-term condition, as noted in the dry state, was maintained when fitted to the concrete [7].
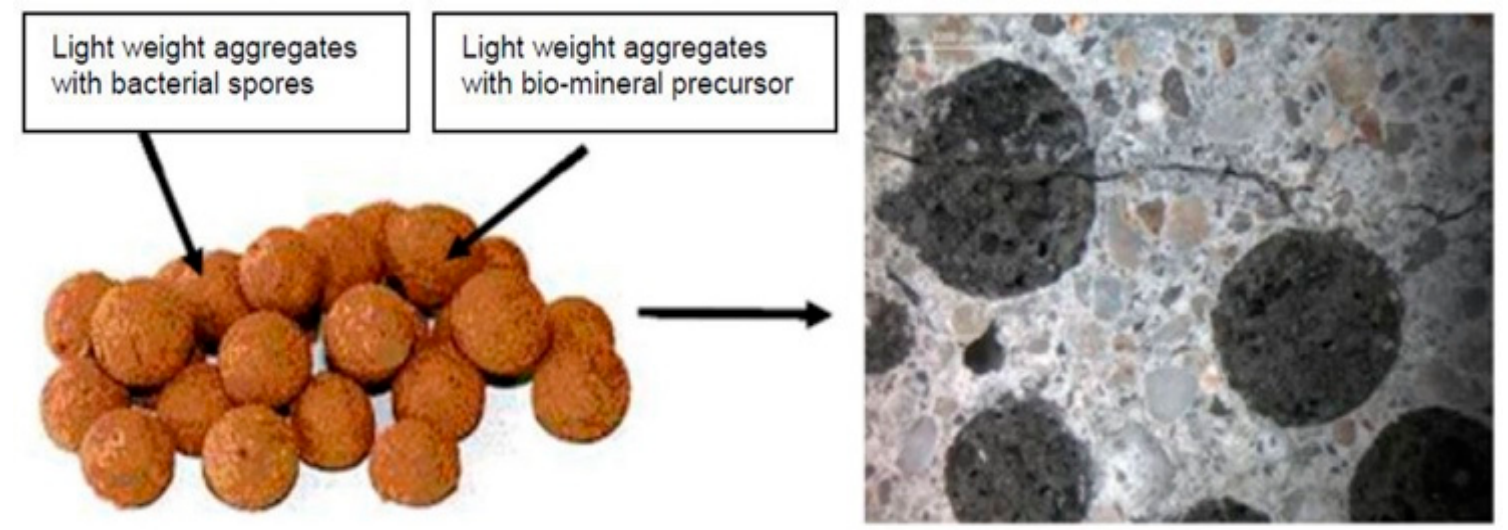

Figure 3. Self-healing blend consisting of expanded clay particles (left) loaded with bacterial spores and mineral biological compound (calcium lactate). When incorporated into concrete (to the right), 
these particles represent reservoirs containing the cited mixture forming the healing agent Error! Reference source not found.. 


\subsection{Evidence of Bacterial Self Regeneration}

Specimens prepared with part of the dense aggregate replaced by expanded clay particles of similar size loaded with the self-regenerating biochemical agent were used to test the bacterial healing of concrete cracks. The amount of light aggregate represents $50 \%$ of the total volume added. Control samples had a resembling aggregate composition, but with expanded clay particles not loaded with the biochemical agent.

The self-repair capability of pre-cracked concrete discs $(10 \mathrm{~cm}$ in diameter, $1.5 \mathrm{~cm}$ thick), serrated from 56-day-cured concrete cylinders was tested by measuring the evolution of water transport through of the discs and later with the permeability test. A deformation-controlled division test produced the formation of cracks in concrete sample disks $-0.15 \mathrm{~mm}$ width running through the sample completely (Figure 4, left). Both sets of control specimens and bacterial concrete (6 of each) were submerged in tap water at room temperature for two weeks, and the permeability was quantified by recording the percolation of tap water over $24 \mathrm{~h}$ (Figure 4, right).

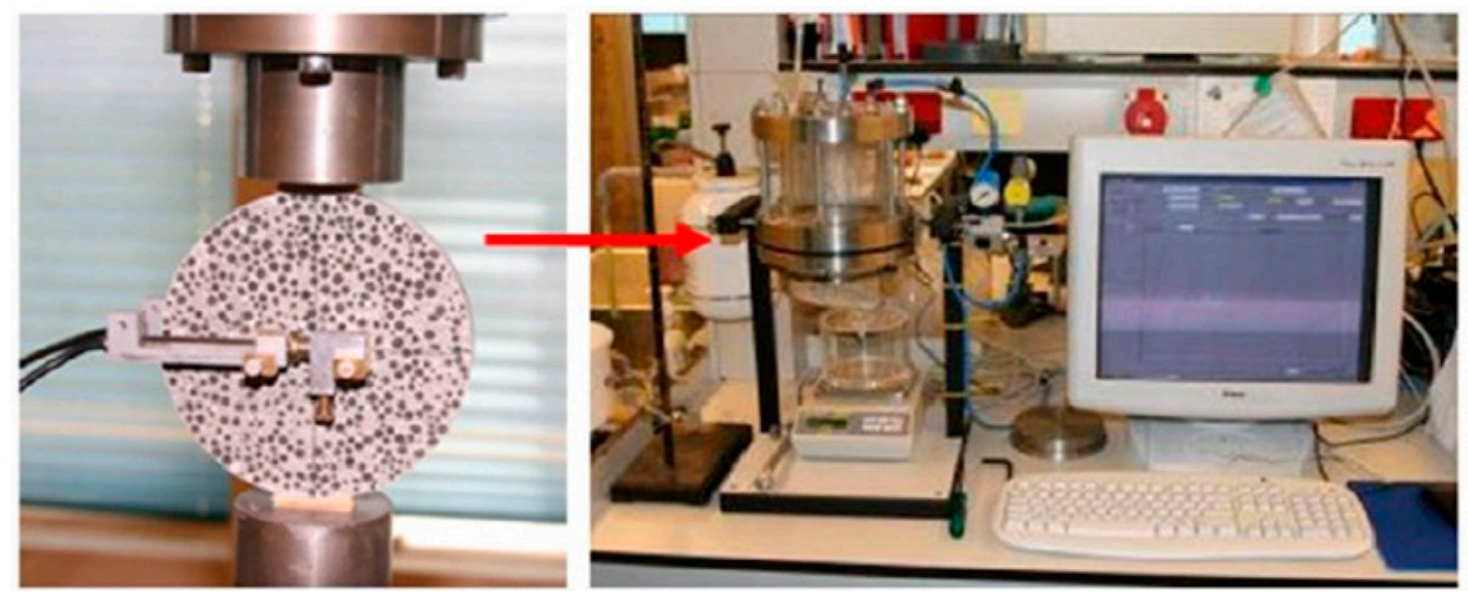

Figure 4. Pre-cracking of the concrete slab and subsequent permeability testing Error! Reference source not found.

A comparison between the samples revealed a significant difference in permeability. While the fissures of the six bacterial specimens were utterly sealed, resulting in no measurable permeability (percolation of $0 \mathrm{~mL}$ water/h), only two of the six control specimens appeared cured. The other four control samples presented permeability values (water percolation) between 0 and $2 \mathrm{~mL} / \mathrm{h}$.

Microscopic examination of cracks on the side exposed to water revealed that, in control samples as well as in bacterial specimens, precipitation of calcium carbonate-based minerals occurred. However, in the control samples, mainly near the edge of the fissure, leaving its main parts unhealed, while efficient and complete healing occurred in the bacterial ones with mineral precipitation predominantly within the crack (Figure 5).

The overall conclusion of these researches was that the bi-component biochemical healing agent (composed of bacterial spores and an appropriate organic cement precursor compound) is a promising and therefore sustainable bio-based alternative for products strictly chemical or cementbased curing agents [6,7]. 

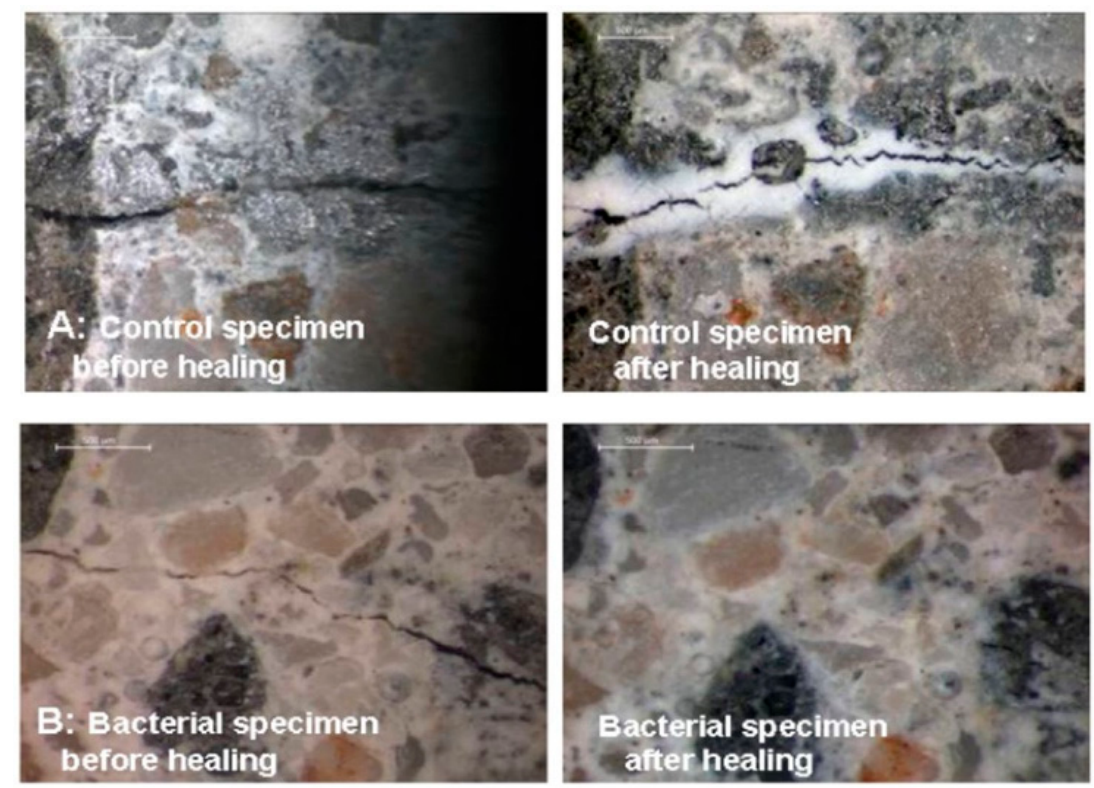

Figure 5. Images of pre-cracked control (A) and bacterial (B) concrete specimen before and after healing [6].

\section{Economic Considerations}

The production of self-regenerating materials generally exceeds the costs of traditional materials. What justifies this additional initial value is the reduction of inspection, maintenance and repair costs plus a longer lifespan, one of the desires of those who handle building constructions.

According to Gonçalves apud Souza and Ripper, budgets and tangible maintenance programs have their elaboration based on the notions of useful life and the deterioration curve of the materials used. Although the financial question has a significant influence on the decisions between preventive and corrective actions, the practice shows that the costs with the prevention do not excel to those of correction [8].

By dismembering the construction steps (Figure 6), according to Gonçalves apud Helene it is possible to stipulate the impact of the cost of the actions in each one - from 1 in the Project Phase to 125 times higher when in the Corrective Maintenance Phase-demonstrating that maintenance can be more burdensome and laborious the longer the delay of its onset [8]. This impact is also evident when we analyze through the Life Cycle Cost of a structure (Figure 7), whose concept encompasses not only the design and construction phase but also the operation and maintenance of the structure, that is, its entire period of existence [9].

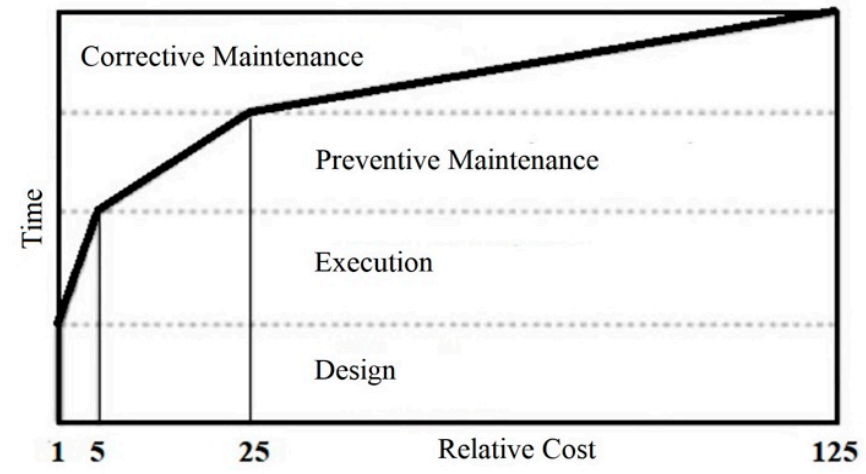

Figure 6. The Law of Fives [7]. 


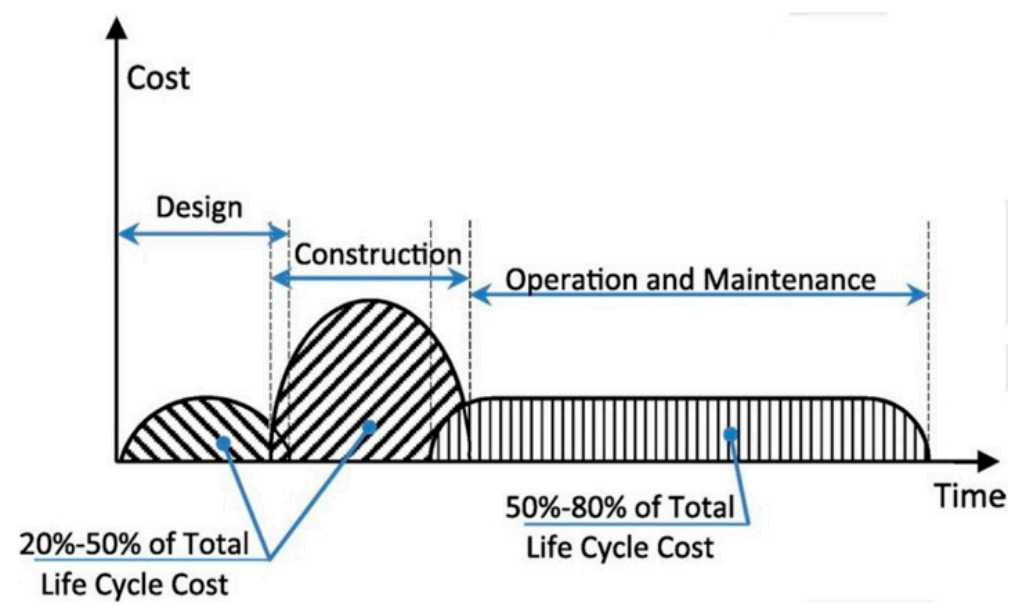

Figure 7. Life Cycle Cost [8].

In Figure 8a,b, the performances and costs of a low-quality (curve A) and high quality (curve B) structure, both of which designed according to the DPP, are compared. Figure 9a,b shows the curves for a system designed according to the DCP. Although schematic, this comparison between the two systems illustrates that, depending on the lifetime required for the structure, the higher initial costs compensate. If the indirect expenses of the repair work were considered-which is not the case in Figures $8 \mathrm{~b}$ and $9 \mathrm{~b}-$ the higher initial values are almost always justified [5].

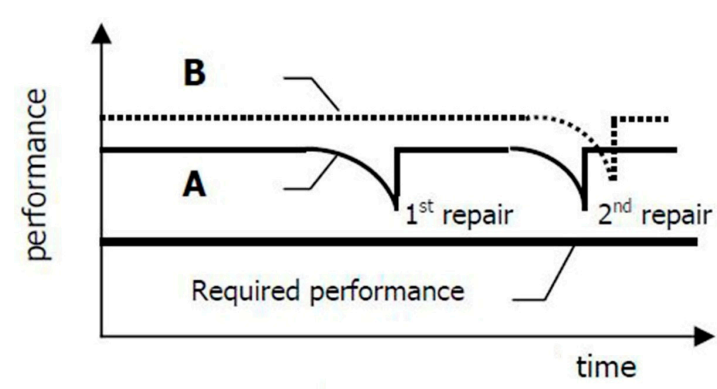

(a)

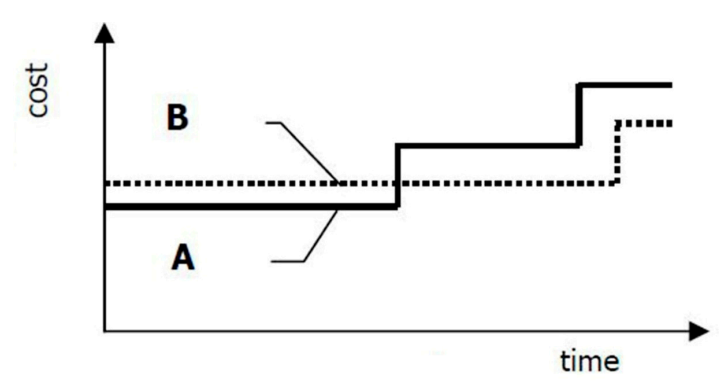

(b)

Figure 8. Performance (a) and cost (b) over time for low (A) and high (B) structures. Direct repair costs included. Interest and inflation not considered Error! Reference source not found..

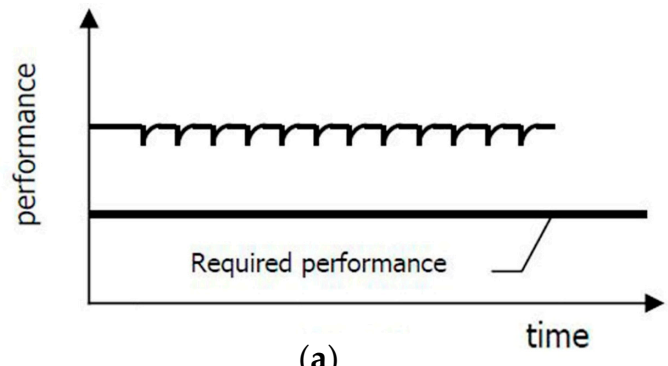

(a)

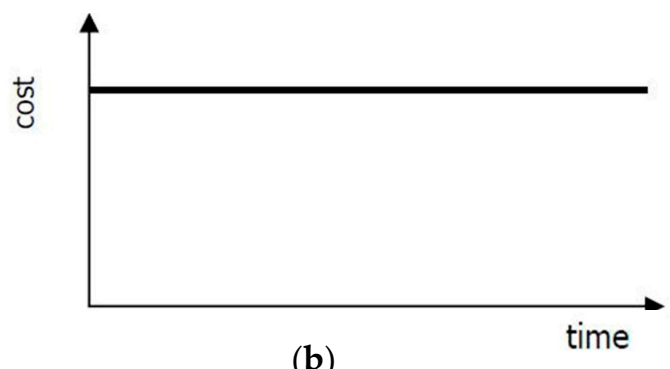

(b)

Figure 9. Performance (a) and cost (b) over time of a structure made with self-regenerating material (concrete). Interest and inflation not considered Error! Reference source not found..

Although Figure 9a suggests the performance of an ideal self-healing material, self-healing and potential self-repair will be limited, so it is unrealistic to expect that the use of such materials will make completely dispensable the inspections, monitoring, maintenance, and repair.

However, the construction industry may already benefit from incremental improvements in the self-regeneration capacity of a material due to the significant use of concrete, which makes small enhancements in material performance already result in substantial savings once that the period without maintenance can be extended and the time of repair can be delayed. Besides situations where 
degradation of a structure should be avoided at all costs due to extremely high consequences in case of failure (e.g., radioactive waste leakage). In such cases, the use of a robust self-regenerating material may be the only solution, and the cost of the material will not be a limiting factor if its use is the only realistic solution.

\section{Final Considerations}

The fast growth of the world's population and expanding economies are two of the main reasons for the growing demand for buildings and infrastructure. Large amounts of raw materials and energy are needed to meet this demand and, as has been discussed previously, in most cases, concrete is the primary building material for these structures.

The lack of quality in the construction results in premature maintenance and repair or even dismantling and demolition of structures. Since even structures with proper quality suffer from the ageing of the materials from which they were built, projects with inherent potential for selfregeneration would extend the life of concrete structures and thus lessen the pressure on the need for new construction, as well as significant savings in maintenance and conservation costs.

In this work, it was possible to verify that the use of a type of concrete that can alone repair its cracks would have significant advantages in the construction of new structures. Also, understand how self-regenerating concrete is made, that the concepts adopted for the development of this material are indeed reliable and accessible and that, despite raising the initial cost of a structure, the final values are balanced or even lower due to the lesser need for maintenance and conservation and to extend its life. Therefore, the adoption of self-regenerating concrete is of great advantage for the Civil Construction Industry.

\section{References}

1. Villanueva, M.; Vazquez, E.; Nobrega, J.; Miranda, R.; Mussi, J.A.; Alves, L. Evaluation of the Maintenance Management Associated with the Performance of a Public Building. J. Civ. Eng. Archit. 2017, 11, 448-454. doi:10.17265/1934-7359/2017.05.005.

2. Porto, T.B.; Fernandes, D.S.G. Curso Básico de Concreto Armado: Conforme NBR 6119/2014; Oficina de Textos: São Paulo, Brazil, 2015. (In Portuguese)

3. Silva, L.; de Albuquerque eLüke, B.-H. Engenharia Civil 1: Perito Criminal Federal (in Portuguese); Saraiva: São Paulo, Brazil, 2013.

4. Dal molín, Denise Capanema Coitinho. Fissuras em Estruturas de Concreto Armado: Análise de Manifestações Típicas e Levantamento de Casos Ocorridos no Estado do Rio Grande do Sul. Master's Thesis, Universidade Federal do Rio Grande do Sul-Escola de Engenharia, Porto Alegre, Brazil, 1988. (In Portuguese)

5. Van Breugel, K. Self-healing Material Concepts as Solution for Aging Infrastructure. In Proceedings of the 37th Conference on Our World in Concrete \& Structures, Singapore, 29-31 August 2012.

6. Jonkers, H.M.; Thijssen, A.; Muyzer, G.; Copuroglu, O.; Schlangen, E. Application of bacteria as self-healing agent for the development of sustainable concrete. Ecol. Eng. J. 2010, 230-235.

7. Jonkers, H.M. Bacteria-based self-healing concrete Special Edition: Self-healing Materials. HERON $2011,56$.

8. Gonçalves, E.A.B. Estudo Das Patologias e Suas Causas Nas Estruturas de Concreto Armado de Obras de Edificações; Undergraduate Thesis, Universidade Federal do Rio de Janeiro-Escola Politécnica, Rio de Janeiro, Brazil, 2015. (In Portuguese)

9. Alves L.; Gremion N.; Figueiredo F.; Vazquez E. Application of Management and Control Techniques in Brazilian Construction Industry. Cur Trends Civil Struct Eng. 2019, 2, CTCSE.MS.ID.000545.

(C) 2019 by the authors. Licensee MDPI, Basel, Switzerland. This article is an open access article distributed under the terms and conditions of the Creative Commons Attribution (CC BY) license (http://creativecommons.org/licenses/by/4.0/). 